Folia Oeconomica Stetinensia

\title{
DETERMINATION OF IMPACT OF PROPENSITIES BY MEANS OF RESIDUALS OF ECONOMETRIC MODELS FOR SPATIAL DATA
}

\author{
Mariusz Doszyń, Ph.D. \\ Department of Econometrics and Statistics \\ Faculty of Economics and Management \\ University of Szczecin \\ Mickiewicza 64, 71-101 Szczecin \\ e-mail:mariusz.doszyn@gmail.com
}

Received 24 November 2009, Accepted 8 June 2010

\begin{abstract}
It is important to be aware that economic occurrences depend also on subjective (psychological and sociological) factors. In many cases these causes could be identified with propensities. Propensities could be understood as a generalized psychological and sociological causes that make probabilities of certain events higher in given objective circumstances. In the article proposition of determining impact of propensities on economic phenomena by means of residuals of econometric models for spatial data was discussed. Econometric consequences of omitting subjective factors (propensities) while analyzing socio-economic regularities were presented. Such kind of residuals as OLS, predictive, studentized, recursive and BLUS residuals were described. Econometric properties of mentioned residuals were also pointed out. In the empirical example all types of residuals were used to analyze impact of propensity to consume in chosen European countries in 2006.
\end{abstract}

Keywords: propensities, propensity to consumption, residuals of econometric models, OLS residuals, predictive residuals, studentized residuals, recursive residuals, BLUS residuals.

JEL classification: C50, C51, C52, E21. 
Subjective phenomena are usually unobservable but their influence in some cases is possible to determine. In many cases subjective factors could be identified with propensities ${ }^{1}$.

The main aim of this paper is to present how impact of propensities could be identified by means of residuals of properly specified econometric models. It could be useful while analyzing impact of propensity to consumption (saving, investment, money storing) on consumption (savings, investments, money supply).

\section{Analysis of influence of propensities on economic phenomena be means of residuals of econometric models}

In general, impact of propensities on economic phenomena could be estimated by adding dummy variables as explanatory variables or by eliminating impact of propensities from all variables in the model. These conclusions come from Frisch-Waugh-Stone theorem ${ }^{2}$. Dummy variable is equal one if object exhibits given propensity and zero otherwise.

Suppose that there is a following model:

$$
y=X_{1} \beta_{1}+X_{2} \beta_{2}+u,
$$

where:

$y$ - vector of observations made on dependent variable,

$X_{1}, X_{2}$ - matrixes of observations made on explanatory variables where first matrix contains objectives factors and the second - variables exhibiting subjective causes (propensities),

$u$ - error term.

The normal equations for (1) $\operatorname{are}^{3}$ :

$$
\left[\begin{array}{cc}
X_{1}^{\prime} X_{1} & X_{1}^{\prime} X_{2} \\
X_{2}^{\prime} X_{1} & X_{2}^{\prime} X_{2}
\end{array}\right]\left[\begin{array}{l}
\beta_{1} \\
\beta_{2}
\end{array}\right]=\left[\begin{array}{l}
X_{1}^{\prime} y \\
X_{2}^{\prime} y
\end{array}\right],
$$

so

$$
\hat{\beta}_{1}=\left(X_{1}^{\prime} X_{1}\right)^{-1} X_{1}^{\prime}\left(y-X_{2}^{\prime} \hat{\beta}_{2}\right) .
$$

Estimates of parameters next to variables consisted in $X_{1}$ might be correctly calculated if subjective factors $\left(X_{2}\right)$ are taken into account. Omitting variables present in $X_{2}$ makes $\hat{\beta}_{1}$ biased by factor $\left(X_{1}^{\prime} X_{1}\right)^{-1} X_{1}^{\prime} X_{2}^{\prime} \hat{\beta}_{2}$. 
After few transformations we know that ${ }^{4}$ :

$$
\hat{\beta}_{2}=\left(X_{2}^{\prime} M_{1} X_{2}\right)^{-1} X_{2}^{\prime} M_{1} y,
$$

where $M_{1}=I-X_{1}\left(X_{1}^{\prime} X_{1}\right)^{-1} X_{1}^{\prime}$ or equivalently:

$$
\hat{\beta}_{2}=\left(X_{2}^{* \prime} X_{2}^{*}\right)^{-1} X_{2}^{* \prime} y^{*} \text {, }
$$

where $X_{2}^{*}=M_{1} X_{2}, y^{*}=M_{1} y$.

Equations (4)-(5) show that impact of propensities could be estimated after elimination of influence of variables being objective factors that appear in matrix $X_{1}$.

In case of spatial data influence of propensities could manifest itself as large residuals in properly specified econometric models. By properly specified model, it is understood model including all important objective factors. Statistically significant residuals in some cases might be treated as an effect of impact of propensities ${ }^{5}$. Residuals in many cases reflect some aspects of economic behavior.

While analyzing impact of propensities, in case of small samples, it is better to use residuals different than OLS residuals because they exhibit autocorrelation and heteroscedasticity even if error term has constant variance and is not autocorrelated.

In case of model $y=X \beta+u$ OLS residuals are equal $\hat{u}=y-X\left(X^{\prime} X\right)^{-1} X^{\prime} y$. If $H=X\left(X^{\prime} X\right)^{-1} X^{\prime}$ we can see that:

$$
\hat{u}=(I-H) y=(I-H)(X \beta+u)=(I-H) u,
$$

because $H X=X$.

Covariance matrix of (6) has the form $V^{2}(\hat{u})=(I-H) \sigma^{2}$, so residuals are heteroscedastic and autocorrelated because $\mathrm{H}$ is not diagonal. Instead of OLS residuals, predictive, studentized, recursive and BLUS residuals are often used ${ }^{6}$. Predictive residual is equal $u_{i}^{*}=y_{i}-\hat{y}(i)$ where $\hat{y}(i)$ is a forecast made by means of model estimated with exclusion of $i$-th observation.

Relation between OLS and predictive residuals could be expressed as:

$$
u_{i}^{*}=\hat{u}_{i} /\left(1-h_{i}\right)
$$

where $h_{i}$ is $i$-th diagonal element of $H$ matrix.

Because in case of OLS residuals $V^{2}\left(\hat{u}_{i}\right)=\left(1-h_{i}\right) \sigma^{2}$ so $V^{2}\left(u_{i}^{*}\right)=\sigma^{2} /\left(1-h_{i}\right)$. As we can see predictive residuals are also heteroscedastic and autocorrelated but they are helpful in identification of untypical observations ${ }^{7}$.

Studentized residual is calculated as a predictive residual divided by its standard error: 


$$
\tilde{u}_{i}=u_{i}^{*} /\left(S(i)\left(1-h_{i}\right)^{0,5}\right),
$$

where $S^{2}(i)$ is an estimated variance of residuals without $i$-th observation.

Predictive and studentized residuals could be also obtained by using dummy variables that are equal one for $i$-th observation and zero otherwise. The estimate of parameter next to dummy variable is a predictive residual and its $t$ value is a studentized residual. Dummy variables defined in that way show impact of subjective factors (propensities).

Recursive residuals are homoscedastic and not autocorrelated. To estimate them, model for first $i$ observation should be calculated (observations should be somehow ordered). Afterwards forecast for next observation $\tilde{y}_{i+1}$ is computed. Error of prediction equals $e_{i+1}=y_{i+1}-\tilde{y}_{i+1}$. Variance of prediction takes the form $V^{2}\left(e_{i+1}\right)=d_{i+1}^{2} \sigma^{2}$, where $\sigma^{2}$ is a variance of an error term in the (before) estimated model.

Recursive residuals are obtained as:

$$
\tilde{u}_{i+1}=e_{i+1} / d_{i+1} .
$$

This procedure is then continued for all remained observations.

H. Theil has proposed BLUS (Best Linear Unbiased Scalar) residuals that, similarly as recursive residuals, are homoscedastic and not autocorrelated ${ }^{8}$ :

$$
\hat{\varepsilon}_{1}=e_{1}-X_{1} X_{0}^{-1}\left[\sum_{h=1}^{H} \frac{d_{h}}{1+d_{h}} q_{h} q_{h}^{\prime}\right] e_{0},
$$

where:

$e_{1}-(n-k)$ OLS residuals ( $n$ - number of observations, $k$ - number of parameters),

$e_{0}-k$ first OLS residuals,

$X_{1}$ - part of matrix of independent variables $(X)$ with $(n-k)$ rows and $k$ columns,

$X_{0}$ - part of matrix of independent variables $(X)$ with $k$ rows and $k$ columns,

$d_{h}^{2}(h=1,2, \ldots, H)$ - characteristic roots of $X_{0}\left(X^{\prime} X\right)^{-1} X_{0}^{\prime}$,

$q_{1}, q_{2}, \ldots, q_{H}-$ characteristic vectors related to $d_{h}^{2}$.

\section{Empirical analysis of impact of propensity to consume on consumption spending}

In empirical example all presented types of residuals were used to analyze the impact of propensity to consumption in chosen European countries in 2006. As variables, consumption per capita $\left(c_{i}\right)$, income per capita $\left(y_{i}\right)$ and long - term interest rate $\left(r_{i}\right)$ in logarithmic 
form were taken. As a long-term interest rate interest of 10-years bond yields was assumed but impact of this variable was insignificant (on significance level 0.05).

Estimated model $c_{i}=\alpha_{0}+\alpha_{1} y_{i}+\varepsilon_{t}$ used to calculate OLS residuals has the form (in this model dummy variable is of course not present):

$$
\hat{c}_{i}=0.743+0.866 y_{i}, S_{e}=0.111, \bar{R}^{2}=0.970, p_{\text {emp }}=0.297 .
$$

Models applied to compute predictive, studentized and recursive residuals are presented in the Appendix.

Estimated models are well fitted to empirical data. Adjusted determination ratio $\left(\bar{R}^{2}\right)$ is usually higher than $0.9 . F$ test indicates significant simultaneous impact of explanatory variables. Empirical significance levels $\left(p_{e m p}\right)$ in Doornik-Hansen test confirms normality of residuals (significance level $\alpha=0.05$ ).

In case of OLS, predictive, recursive and BLUS residuals it was assumed that impact of propensities is significant if $\left|e_{i}\right|>2 S_{e}$, where $e_{i}$ is a residual for $i$-th object and $S_{e}$ is a standard error of OLS residuals. For studentized residuals significance is implied by inequality $\left|e_{i}\right|>2$. Residuals used to identify the impact of propensity to consume are presented in Table 1. Countries are ordered with respect to income per capita.

Table 1. OLS, predictive, studentized, recursive and BLUS residuals exhibiting impact of propensity to consume in chosen European countries in $20062 S_{e}=0.222$

\begin{tabular}{|c|l|r|r|r|r|r|}
\hline S.n. & \multicolumn{1}{|c|}{ Country } & \multicolumn{1}{c}{ OLS } & Predictive & Studentized & Recursive & BLUS \\
\hline 1 & Bulgaria & 0.023 & 0.034 & 0.246 & - & - \\
\hline 2 & Latvia & -0.022 & -0.026 & -0.210 & - & - \\
\hline 3 & Lithuania & 0.022 & 0.026 & 0.210 & - & 0.022 \\
\hline 4 & Poland & -0.034 & -0.040 & -0.326 & -0.028 & -0.034 \\
\hline 5 & Slovakia & -0.125 & -0.140 & -1.210 & -0.085 & -0.124 \\
\hline 6 & Hungary & -0.143 & -0.158 & -1.391 & -0.066 & -0.142 \\
\hline 7 & Portugal & 0.126 & 0.133 & 1.177 & 0.193 & 0.130 \\
\hline 8 & Slovenia & -0.024 & -0.025 & -0.213 & -0.015 & -0.019 \\
\hline $\mathbf{9}$ & Greece & $\mathbf{0 . 2 8 3}$ & $\mathbf{0 . 2 9 7}$ & $\mathbf{3 . 1 7 6}$ & $\mathbf{0 . 2 3 1}$ & $\mathbf{0 . 2 8 8}$ \\
\hline 10 & Spain & 0.080 & 0.085 & 0.736 & -0.029 & 0.087 \\
\hline 11 & Italy & 0.098 & 0.104 & 0.909 & -0.016 & 0.105 \\
\hline 12 & Germany & 0.037 & 0.039 & 0.334 & -0.075 & 0.044 \\
\hline 13 & France & 0.050 & 0.053 & 0.455 & -0.047 & 0.057 \\
\hline 14 & Belgium & -0.043 & -0.046 & -0.393 & -0.125 & -0.035 \\
\hline 15 & Austria & 0.050 & 0.054 & 0.455 & -0.021 & 0.057 \\
\hline 16 & United Kingdom & 0.130 & 0.141 & 1.237 & 0.056 & 0.138 \\
\hline 17 & Finland & -0.058 & -0.063 & -0.537 & -0.128 & -0.050 \\
\hline 18 & Netherlands & -0.119 & -0.129 & -1.127 & -0.172 & -0.111 \\
\hline 19 & Sweden & -0.119 & -0.130 & -1.131 & -0.154 & -0.110 \\
\hline 20 & Denmark & -0.064 & -0.072 & -0.601 & -0.087 & -0.055 \\
\hline 21 & Ireland & -0.146 & -0.165 & -1.440 & -0.155 & -0.137 \\
\hline
\end{tabular}

Source: own calculations. 
All kinds of residuals show that significant impact of propensity to consume has taken place in Greece were OLS, predictive, recursive and BLUS residuals were higher than double standard error $2 S_{e}=0.222$ and studentized residual was higher than 2 .

To sum up, in case of spatial data impact of propensities could by analyzed by means of residuals exhibiting subjective aspects of economic behavior. Because of lack of heteroscedasticity and autocorrelation (if they are absent) recursive and BLUS residuals are recommended. Empirical analysis of consumption in European countries has indicated significant influence of propensity to consume in Greece in 2006.

\section{Notes}

${ }^{1}$ Problems of propensities are presented, for example, in Doszyń (2009), Doszyń (2008b). Hozer, Doszyń (2004), Hozer (2002).

${ }^{2}$ Johansen (2006).

${ }^{3}$ Greene (2003).

${ }^{4}$ Greene (2003).

${ }^{5}$ Doszyń (2008a).

${ }^{6}$ Maddala (2006).

${ }^{7}$ Maddala (2006).

${ }^{8}$ Detailed description of BLUS residuals and their properties are presented in Theil (1979).

\section{References}

Doszyń, M. (2009). Considerations concerning impact of propensities on basic macroeconomic variables. Folia Oeconomica Stetinensia, 7(15), 109-116, DOI: 10.2478/v10031-0080029-4.

Doszyń, M. (2008a). Metody analizy wpływu skłonności do konsumpcji na wydatki ludności. Wiadomości Statystyczne, 9, 70-76, Warszawa: GUS, PTS.

Doszyń, M. (2008b). Statystyczno-ekonometryczna analiza skłonności ludzkich. Szczecin: Wydawnictwo Naukowe Uniwersytetu Szczecińskiego.

Greene, W. (2003). Econometric Analysis. Fifth Edition. New Jersey: Prentice Hall.

Hozer, J., Doszyń M. (2004). Ekonometria skłonności. Warszawa: PWE. 
Hozer, J. (2002). Ekonometryczna interpretacja skłonności w ekonomii. Przegląd Statystycz$n y, 3$.

Johansen, S. (2006). Cointegration: a survey. Palgrave Handbook of Econometrics: Volume 1, Econometric Theory. Basingstoke, UK and New York, USA: Palgrave MacMillan.

Keynes, J. (2003). Ogólna teoria zatrudnienia, procentu i pieniadza. Warszawa: PWN.

Maddala, G. (2006). Ekonometria. Warszawa: PWN.

Popper, K. (1959). The Propensity Interpretation of Probability. British Journal for the Philosophy of Science, 10.

Samuelson, P. (1970). Foundations of Economic Analysis. New York: Atheneum.

Theil, H. (1979). Zasady ekonometrii. Warszawa: PWN.

\section{Appendix}

Table A1. Consumption models $c_{i}=\alpha_{0}+\alpha_{1} y_{i}+\alpha_{2} d_{i}+u_{i}$ for chosen European countries in 2006 with income per capita $\left(y_{i}\right)$ and dummy variable $\left(d_{i}\right)$ as explanatory variables used to calculate predictive and studentized residuals*

\begin{tabular}{|c|c|c|c|c|c|c|c|}
\hline S.n. & $\hat{\alpha}_{0}$ & $\hat{\alpha}_{1}$ & $\hat{\alpha}_{2}$ & $S_{e}$ & $\bar{R}^{2}$ & $F$ & $p_{\text {emp }}$ \\
\hline 1 & 0.688 & 0.872 & 0.034 & 0.114 & 0.968 & 307.350 & 0.273 \\
\hline 2 & 0.767 & 0.864 & -0.026 & 0.114 & 0.968 & 307.063 & 0.307 \\
\hline 3 & 0.719 & 0.868 & 0.026 & 0.114 & 0.968 & 307.069 & 0.276 \\
\hline 4 & 0.780 & 0.863 & -0.040 & 0.114 & 0.968 & 308.152 & 0.307 \\
\hline 5 & 0.852 & 0.856 & -0.140 & 0.110 & 0.971 & 331.919 & 0.224 \\
\hline 6 & 0.856 & 0.855 & -0.158 & 0.108 & 0.971 & 340.199 & 0.207 \\
\hline 7 & 0.711 & 0.869 & 0.133 & 0.110 & 0.971 & 330.549 & 0.142 \\
\hline 8 & 0.749 & 0.866 & -0.025 & 0.114 & 0.968 & 307.087 & 0.309 \\
\hline 9 & 0.744 & 0.865 & 0.297 & 0.091 & 0.980 & 483.031 & 0.709 \\
\hline 10 & 0.755 & 0.864 & 0.085 & 0.112 & 0.969 & 315.786 & 0.196 \\
\hline 11 & 0.769 & 0.863 & 0.104 & 0.111 & 0.970 & 320.770 & 0.171 \\
\hline 12 & 0.757 & 0.864 & 0.039 & 0.114 & 0.968 & 308.248 & 0.253 \\
\hline 13 & 0.763 & 0.864 & 0.053 & 0.113 & 0.969 & 309.920 & 0.235 \\
\hline 14 & 0.724 & 0.868 & -0.046 & 0.113 & 0.969 & 308.994 & 0.313 \\
\hline 15 & 0.767 & 0.863 & 0.054 & 0.113 & 0.969 & 309.913 & 0.234 \\
\hline 16 & 0.809 & 0.859 & 0.141 & 0.109 & 0.971 & 333.081 & 0.128 \\
\hline 17 & 0.714 & 0.869 & -0.063 & 0.113 & 0.969 & 311.341 & 0.306 \\
\hline 18 & 0.678 & 0.873 & -0.129 & 0.110 & 0.970 & 328.533 & 0.238 \\
\hline 19 & 0.673 & 0.874 & -0.130 & 0.110 & 0.970 & 328.681 & 0.238 \\
\hline 20 & 0.694 & 0.872 & -0.072 & 0.113 & 0.969 & 312.623 & 0.302 \\
\hline 21 & 0.627 & 0.879 & -0.165 & 0.108 & 0.972 & 342.613 & 0.219 \\
\hline
\end{tabular}

* As a $p_{\text {emp }}$ empirical significance level in Doornik-Hansen normality test is understood Source: own calculations. 
Table A2. Consumption models $c_{i}=\beta_{0}+\beta_{1} y_{i}+\beta_{2} d_{i}+\varepsilon_{i}$ for chosen European countries in 2006 with income per capita $\left(y_{i}\right)$ and dummy variable $\left(d_{i}\right)$ as explanatory variables used to calculate recursive residuals*

\begin{tabular}{|c|c|c|c|c|c|c|c|}
\hline S.n. & $\hat{\beta}_{0}$ & $\hat{\beta}_{1}$ & $\hat{\beta}_{2}$ & $S_{e}$ & $\bar{R}^{2}$ & $F$ & $p_{\text {emp }}$ \\
\hline 4 & 1.013 & 0.836 & -0.034 & 0.031 & 0.990 & 146.519 & - \\
\hline 5 & 1.142 & 0.820 & -0.106 & 0.030 & 0.989 & 180.385 & - \\
\hline 6 & 1.616 & 0.763 & -0.079 & 0.055 & 0.957 & 56.289 & - \\
\hline 7 & 1.927 & 0.726 & 0.284 & 0.058 & 0.980 & 144.778 & - \\
\hline 8 & 0.502 & 0.891 & -0.019 & 0.101 & 0.946 & 62.729 & 0.826 \\
\hline 9 & 0.567 & 0.883 & 0.290 & 0.092 & 0.971 & 132.736 & 0.541 \\
\hline 10 & -0.284 & 0.980 & -0.036 & 0.122 & 0.955 & 96.274 & 0.933 \\
\hline 11 & -0.199 & 0.971 & -0.019 & 0.115 & 0.965 & 136.846 & 0.712 \\
\hline 12 & -0.162 & 0.967 & -0.087 & 0.108 & 0.971 & 182.096 & 0.506 \\
\hline 13 & -0.016 & 0.950 & -0.053 & 0.105 & 0.973 & 218.924 & 0.305 \\
\hline 14 & 0.056 & 0.942 & -0.138 & 0.101 & 0.975 & 257.695 & 0.179 \\
\hline 15 & 0.221 & 0.924 & -0.023 & 0.104 & 0.975 & 271.721 & 0.140 \\
\hline 16 & 0.245 & 0.921 & 0.060 & 0.100 & 0.977 & 324.322 & 0.089 \\
\hline 17 & 0.190 & 0.927 & -0.137 & 0.097 & 0.978 & 357.348 & 0.108 \\
\hline 18 & 0.300 & 0.915 & -0.182 & 0.100 & 0.976 & 352.478 & 0.127 \\
\hline 19 & 0.438 & 0.900 & -0.163 & 0.106 & 0.973 & 324.267 & 0.163 \\
\hline 20 & 0.554 & 0.887 & -0.093 & 0.109 & 0.971 & 322.355 & 0.235 \\
\hline 21 & 0.627 & 0.879 & -0.165 & 0.108 & 0.972 & 342.613 & 0.219 \\
\hline
\end{tabular}

*It was not possible to calculate empirical significance levels $p_{\text {emp }}$ in Doornik-Hansen test for observation numbers smaller than 8

Source: own calculations. 